\title{
Effects of the Substitution of Mischmetal for PrNd on the Microstructures and Magnetic Properties of Rapidly Quenched (MM)PrNd-Fe-B Nanocrystalline Magnets
}

\author{
Zeng-ru Zhao ${ }^{1,2}$, Xin Wang ${ }^{1}$, Xue-feng Zhang ${ }^{1,2 *}$, Qiang Ma ${ }^{1}$, Yan-li Liu ${ }^{1}$, \\ Yong-feng $\mathrm{Li}^{1}$, Fei Liu ${ }^{1}$, and Gao-feng Wang ${ }^{2}$ \\ ${ }^{1}$ School of Science, Inner Mongolia University of Science \& Technology, Baotou 014010, China \\ ${ }^{2}$ Key Laboratory of Integrated Exploitation of Bayan Obo Multi-Metal Resources, Inner Mongolia University of Science \& Technology, \\ Baotou 014010, China
}

(Received 23 November 2016, Received in final form 5 February 2017, Accepted 2 March 2017)

\begin{abstract}
Mischmetal of Bayan Obo ore was utilized to prepare the high performance $\left(\operatorname{Pr}_{7.34} \mathrm{Nd}_{21.86}\right)_{1-\mathrm{x}} \mathrm{MM}_{\mathrm{x}} \mathrm{Fe}_{68.7} \mathrm{Al}_{0.1^{-}}$ $\mathrm{Cu}_{0.12} \mathrm{Co}_{0.88} \mathrm{~B}$ ribbons using melt-spinning method. Phase composition and magnetic properties were investigated at room temperature. The ribbons mainly consist of $\mathbf{R}_{2} \mathbf{F e}_{14} B$ phase in isotropic nanostructure. Both coercivity and maximum energy product decrease with the increase of $\mathrm{MM}$ content. The magnetic parameters of the ribbons with $\mathrm{MM}=20 \%$ in mass are $B_{\mathrm{r}}=7.38 \mathrm{kGs}, H_{\mathrm{cj}}=13.66 \mathrm{kOe},(B H)_{\max }=11.81$ MGOe. Henkel plots were applied to demonstrate the exchange coupling interaction between grains.
\end{abstract}

Keywords : permanent magnets, mischmetal, $\mathrm{R}_{2} \mathrm{Fe}_{14} \mathrm{~B}$, magnetic properties

\section{Introduction}

(PrNd)-Fe-B magnet is widely used and rapidly developed due to its outstanding magnetic performance among various permanent magnets [1-4]. However, $\mathrm{Pr}$ and $\mathrm{Nd}$ elements are less abundant in the natural rare earth resources, comparing with La and Ce [5]. Developing the high abundant rare earth permanent magnets is requisite for both cost reduction and efficient utilization of rare earth resource. Thus, the research on substitution of Pr$\mathrm{Nd}$ by $\mathrm{Ce}$ or mischmetal alloy has been paid much attention [6-19]. Recently, Pathak et al. [13] reported that the maximum energy product of the hot pressed and die upset $\left(\mathrm{Nd}_{0.8} \mathrm{Ce}_{0.2}\right)_{2.4} \mathrm{Fe}_{12} \mathrm{Co}_{2} \mathrm{~B}$ alloy was $31 \mathrm{MGOe}$. Zhu et al. [14] investigated the influence of Ce content on the rectangularity of demagnetization curves and characterized the magnetic properties of $\left(\mathrm{Nd}_{1-\mathrm{x}} \mathrm{Ce}_{\mathrm{x}}\right)_{30}(\mathrm{Fe}, \mathrm{TM})_{\mathrm{bal}} \mathrm{B}_{1}$ sintered magnet prepared by the double main phase alloy method. They found that the maximum energy product of the sintered magnet was still higher than 43 MGOe when the Ce content reached $30 \%$ of the total amount of the

(C)The Korean Magnetics Society. All rights reserved.

*Corresponding author: Tel: +86-158-4881-9058

Fax: +86-472-5954358, e-mail: xuefeng367@163.com rare earth metals. However, the raw materials mentioned above were pure elements separated and purified from the rare earth ore, thus it brought environmental pollution and couldn't achieve comprehensive utilization of the resources.

Instead of the PrNd alloy, the use of mischmetal (MM) of Bayan Obo ore to prepare R-Fe-B magnets is a valuable way for not only environmental protection but also the utilization of rare earth resource. Niu et al. [15] prepared the sintered R-Fe-B magnets containing MM by dual alloy method, and they found that for the atomic ratio $\mathrm{MM} / \mathrm{R}<21.5 \%$ the magnetic properties reached a practical level of $B_{\mathrm{r}} \sim 12.1 \mathrm{kGs}, H_{\mathrm{cj}} \sim 10.7 \mathrm{kOe}$, and $(B H)_{\max }$ $\sim 34.0$ MGOe. But till now, the magnetic properties and microstructures of MM substituted for PrNd in PrNdFe-B have not been studied in details. In this paper, rapidly quenched ribbons with nominal compositions of $\left(\mathrm{Pr}_{7.34} \mathrm{Nd}_{21.86}\right)_{1-\mathrm{x}} \mathrm{MM}_{\mathrm{x}} \mathrm{Fe}_{68.7} \mathrm{Al}_{0.1} \mathrm{Cu}_{0.12} \mathrm{Co}_{0.88} \mathrm{~B} \quad(x=0,0.05$, $0.1,0.15,0.2,0.25$ and 0.5$)$ were prepared, and the effects of the MM substitution for PrNd on the microstructures and the magnetic properties were investigated.

\section{Experimental}

The $\left(\mathrm{Pr}_{7.34} \mathrm{Nd}_{21.86}\right)_{1-x} \mathrm{MM}_{x} \mathrm{Fe}_{68.7} \mathrm{Al}_{0.1} \mathrm{Cu}_{0.12} \mathrm{Co}_{0.88} \mathrm{~B}$ ingots with $x=0,0.05,0.1,0.15,0.2,0.25$ and 0.5 were pre- 
pared by arc melting in an argon atmosphere with high purity. The purities of the starting materials are $99.99 \%$ for $\mathrm{Fe}, 99.23 \%$ for $\mathrm{Fe}-\mathrm{B}$ alloy and $99.72 \%$ for $\mathrm{PrNd}$ alloy. The mischmetal (purity about $99.5 \%$ ) containing about 28.63 wt.\% La, 50.13 wt.\% Ce, 4.81 wt.\% $\mathrm{Pr}$ and 16.38 wt.\% Nd was used in this experiment. Each ingot was re-melted three times to promote the compositional homogeneity. The ribbons were obtained directly by induction melting the ingot in a quartz tube under an argon atmosphere and then ejecting molten alloy through the orifice in quartz crucible onto the edge of a rotating copper wheel. The surface velocity of copper wheel was set in the range of $10-30 \mathrm{~m} / \mathrm{s}$ in order to optimize the magnetic properties. For easy identification, the samples with different MM contents and wheel velocities were named as $\mathrm{A}_{m, v}$, where the subscripts $m$ and $v$ denote the MM content and wheel velocity, respectively. For instance, $\mathrm{A}_{5,20}$ represents the sample with $5 \mathrm{wt} . \%$ of MM prepared using the wheel velocity of $20 \mathrm{~m} / \mathrm{s}$. The phase composition of the ribbons was examined by X-ray diffraction (XRD) using $\mathrm{Cu} \mathrm{K \alpha}$ radiation. Transmission electron microscope (TEM) measurement was carried out in a JEOL, Model JEM-2010. Magnetic measurements were carried out using Qantum Design vibrating sample magnetometer (VSM) at $300 \mathrm{~K}$ with the maximum field of $30 \mathrm{kOe}$.

\section{Results and Discussion}

The hysteresis loops of $\mathrm{A}_{0, v} \mathrm{~A}_{5, v} \mathrm{~A}_{10, v}$ and $\mathrm{A}_{50, v}$ ribbons prepared with different wheel velocities are showed in Fig. 1. One can see that the shapes of the hysteresis loops of the ribbons prepared by melt-spinning technique are strongly dependent on the wheel velocity, especially for the ribbons without MM addition. Namely, the magnetic properties of the studied ribbons can be optimized by adjusting the wheel velocity in sample preparation. On one hand, the ribbons prepared with low wheel velocity (such as $10 \mathrm{~m} / \mathrm{s}$ ) show small values of coercivity and remanence due to the excessive growth of crystalline grains. On the other hand, the ribbons prepared with high wheel velocity (such as $30 \mathrm{~m} / \mathrm{s}$ ) exhibit even characteristics of a soft magnet with high magnetization. Nonacrystalline grains and even amorphous phase could form in the fast cooling process, which results in the disappearance of hard magnetic properties in the ribbons. The wheel velocity has similar effects on the magnetic properties in the ribbons with MM addition. However, one can find that this kind of influences becomes insignificant as the MM content increases. The hysteresis loops almost overlap for different wheel velocities when the MM content is higher than $10 \mathrm{wt} . \%$. It indicates that the
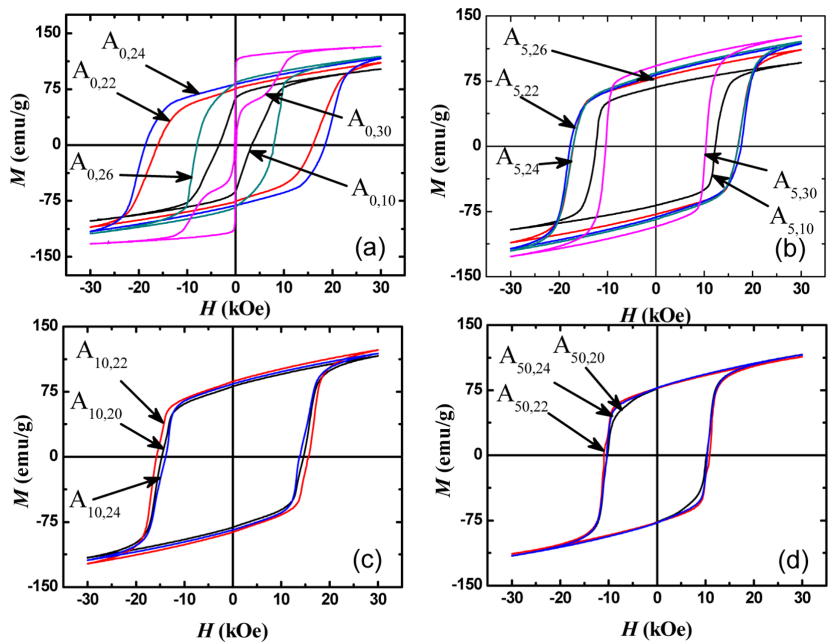

Fig. 1. (Color online) The hysteresis loops of ribbons prepared with different wheel velocities. (a) for $\mathrm{A}_{0, v} ;$ (b) for $\mathrm{A}_{5, v}$; (c) for $\mathrm{A}_{10, v} ;$ (d) for $\mathrm{A}_{50, v}$.

MM doped ribbons with similar and high magnetic properties can be obtained in the fast cooling processes with different cooling rates. This is quite valuable and meaningful for fabricating magnets in industry.

In order to determine the optimal wheel velocity for the studied ribbons, we have plotted the curves of coercivity $H_{\mathrm{cj}}$, the maximum magnetic energy product $(B H)_{\max }$ and remanent magnetizaiton $M_{r}$ as functions of the wheel velocity ( $v$ ) for $\mathrm{A}_{0, v}, \mathrm{~A}_{5, v}, \mathrm{~A}_{10, v}$ and $\mathrm{A}_{50, v}$, as shown in Fig. 2. As the wheel velocity increases, both $H_{\mathrm{cj}}$ and $(B H)_{\max }$ exhibit peaks in the curves, but the $M_{r}$ shows an nearly increasing trend except for few points. We still conclude that the optimum wheel velocities are $24 \mathrm{~m} / \mathrm{s}$ for the MM free ribbons and $22 \mathrm{~m} / \mathrm{s}$ for the MM doped ribbons. The
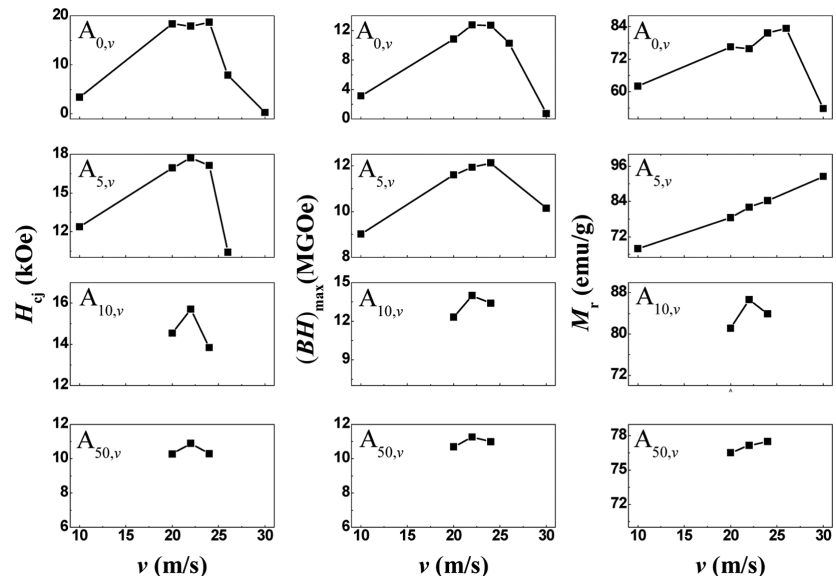

Fig. 2. Magnetic properties including coercivity $H_{\mathrm{cj}}$, the maximum magnetic energy product $(B H)_{\max }$ and remanent magnetization $M_{\mathrm{r}}$ as functions of wheel velocity for $\mathrm{A}_{0, v}, \mathrm{~A}_{5, v}, \mathrm{~A}_{10, v}$ and $\mathrm{A}_{50, v}$. 


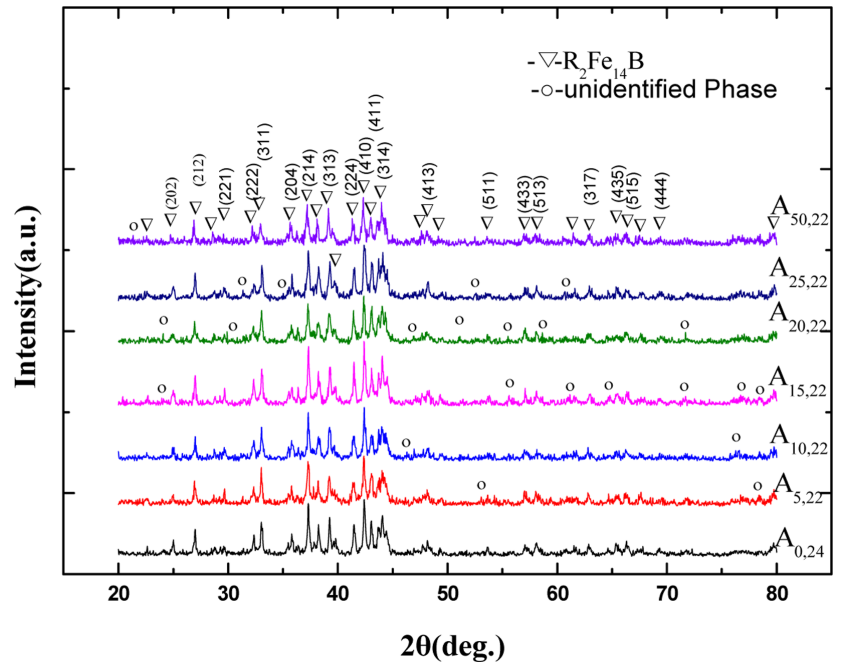

Fig. 3. (Color online) XRD patterns of the optimum wheel velocity of $\left(\operatorname{Pr}_{7.34} \mathrm{Nd}_{21.86}\right)_{1-\mathrm{x}} \mathrm{MM}_{\mathrm{x}} \mathrm{Fe}_{68.7} \mathrm{Al}_{0.1} \mathrm{Cu}_{0.12} \mathrm{Co}_{0.88} \mathrm{~B}$ ribbons.

optimum wheel velocity of the MM free ribbons is slightly higher than that of the MM doped ribbons, which should be attributed to the higher tolerance process parameters of the MM doped ribbons, as reported in Ref. [18].

The coercivity and the remanence of magnet have close relationship with microstructure, such as the grain size and phase structure which could be partially characterized by XRD. The XRD diffraction patterns of optimally meltspun ribbons are displayed in Fig. 3. All of the samples contain the isotropic $\mathrm{R}_{2} \mathrm{Fe}_{14} \mathrm{~B}$ structure phases. It is shown in the XRD patterns that the diffraction peaks are not smooth and there are some weak peaks besides the peaks of the main phase, indicating a small amount of metastable phase and amorphous phase at the intergranular interface in these MM-doped ribbons, which is similar to
Table 1. Crystal lattice constants and room temperature magnetic properties of ribbons prepared with the optimum velocity.

\begin{tabular}{cccccc}
\hline \hline $\begin{array}{c}\text { Sample } \\
\text { No. }\end{array}$ & $\begin{array}{c}a \\
\AA\end{array}$ & $\begin{array}{c}B_{r} \\
\mathrm{kGs}\end{array}$ & $\begin{array}{c}H_{c j} \\
\mathrm{kOe}\end{array}$ & $\begin{array}{c}(B H)_{\max } \\
\mathrm{MGOe}\end{array}$ \\
\hline $\mathrm{A}_{0,24}$ & 8.8165 & 12.2436 & 7.70 & 17.98 & 12.74 \\
$\mathrm{~A}_{5,22}$ & 8.7882 & 12.2090 & 7.33 & 16.93 & 11.92 \\
$\mathrm{~A}_{10,22}$ & 8.7871 & 12.2012 & 7.28 & 15.42 & 11.49 \\
$\mathrm{~A}_{15,22}$ & 8.7846 & 12.1934 & 7.30 & 14.96 & 11.47 \\
$\mathrm{~A}_{20,22}$ & 8.7786 & 12.1930 & 7.38 & 13.66 & 11.81 \\
$\mathrm{~A}_{25,22}$ & 8.7784 & 12.1878 & 7.34 & 12.76 & 11.64 \\
$\mathrm{~A}_{50,22}$ & 8.7546 & 12.1701 & 7.36 & 11.61 & 11.22 \\
\hline
\end{tabular}

the results in Ref. [18]. On the basis of the strong Bragg reflection peaks for $30^{\circ}<2 \theta<45^{\circ}$, we estimate the average grain sizes of the studied ribbons using Scherrer equation and find that the values are in the range of 20-30 $\mathrm{nm}$. The observation of nanocrystals in the ribbons implies excellent magnetic properties of the magnets. In addition, with the increase of MM content, most of diffraction peaks shift to high angle, and result in a slight decrease of lattice constant for the Ce substitution for $\mathrm{Nd}$ in $\mathrm{R}_{2} \mathrm{Fe}_{14} \mathrm{~B}$ [5]. The obtained lattice constants using Jade software are listed in Table 1.

The TEM images of $\left(\operatorname{Pr}_{7.34} \mathrm{Nd}_{21.86}\right)_{0.85} \mathrm{MM}_{0.2} \mathrm{Fe}_{68.7} \mathrm{Al}_{0.1}$ $\mathrm{Cu}_{0.12} \mathrm{Co}_{0.88} \mathrm{~B}$ are shown in Fig. 4. The average grain size is about $30 \mathrm{~nm}$, which coincides with XRD result. Rareearth-rich phase exists in the form of thin layer in Fig. 4(b) and its thickness is about $4 \mathrm{~nm}$. It is well known that the fine microstructure is beneficial to enhancing the exchange interaction between hard magnetic grains. Therefore, a strong exchange coupling interaction may exist in the studied ribbons.

The hysteresis loops of $\left(\mathrm{Pr}_{7.34} \mathrm{Nd}_{21.86}\right)_{1-\mathrm{x}} \mathrm{MM}_{\mathrm{x}} \mathrm{Fe}_{68.7} \mathrm{Al}_{0.1^{-}}$

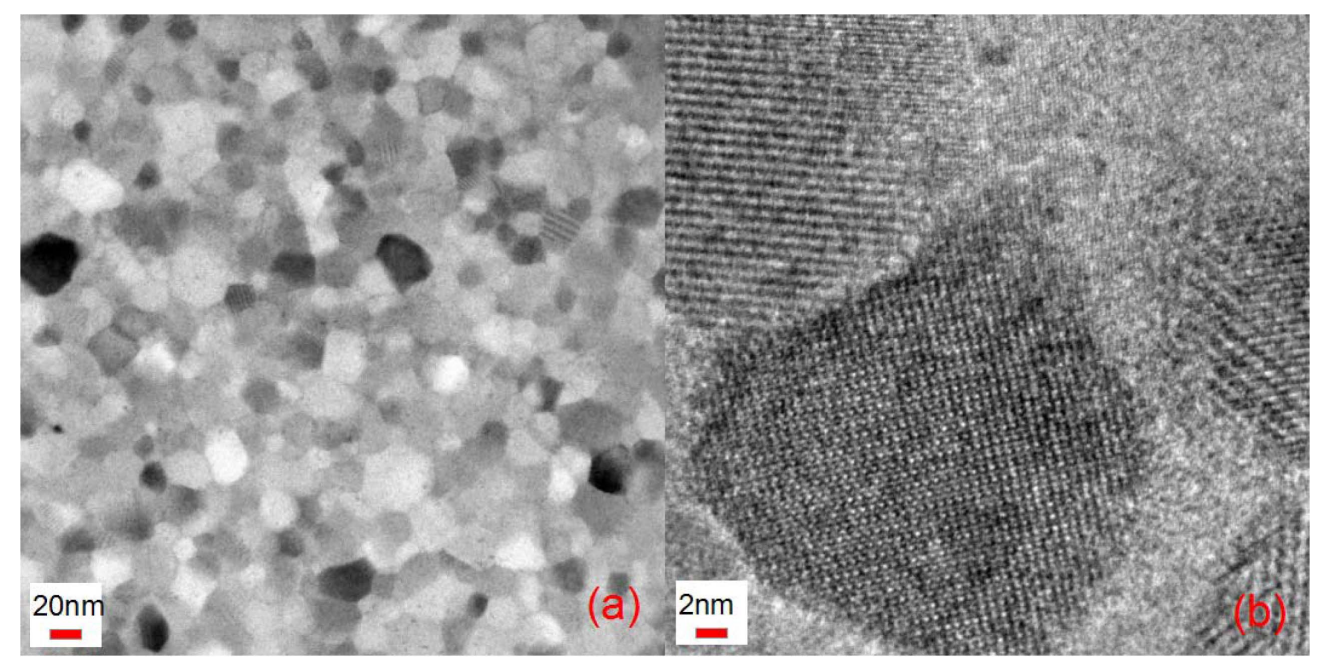

Fig. 4. (Color online) TEM images of $\left(\operatorname{Pr}_{7.34} \mathrm{Nd}_{21.86}\right)_{0.85} \mathrm{MM}_{0.2} \mathrm{Fe}_{68.7} \mathrm{Al}_{0.1} \mathrm{Cu}_{0.12} \mathrm{Co}_{0.88} \mathrm{~B}$ ribbon. 


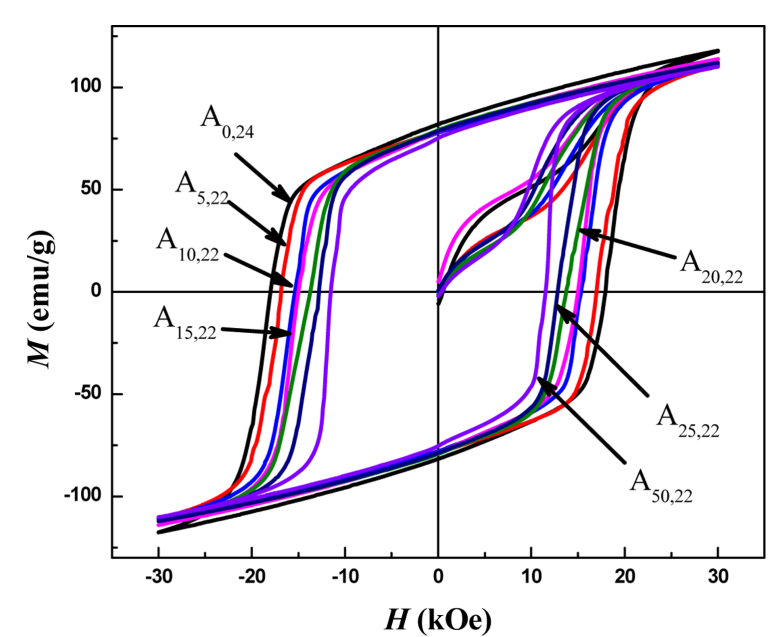

Fig. 5. (Color online) The hysteresis loops of the optimum wheel velocity of $\left(\operatorname{Pr}_{7.34} \mathrm{Nd}_{21.86}\right)_{1-\mathrm{x}} \mathrm{MM}_{\mathrm{x}} \mathrm{Fe}_{68.7} \mathrm{Al}_{0.1} \mathrm{Cu}_{0.12} \mathrm{Co}_{0.88} \mathrm{~B}$ ribbons.

$\mathrm{Cu}_{0.12} \mathrm{Co}_{0.88} \mathrm{~B}$ prepared with the corresponding optimum wheel velocities are displayed in Fig. 5. The values of $B_{r}$, $H_{c j}$, $(B H)_{\max }$ for $\mathrm{A}_{0,24}, \mathrm{~A}_{5,22}, \mathrm{~A}_{10,22}, \mathrm{~A}_{15,22}, \mathrm{~A}_{20,22}, \mathrm{~A}_{25,22}$ and $\mathrm{A}_{50,22}$ are listed in Table 1. For all the samples, the coercivity decreases with increasing MM content. This is due to the fact that the substitution of Ce elements for $\mathrm{Nd}$ in $\mathrm{R}_{2} \mathrm{Fe}_{14} \mathrm{~B}$. Besides, the observation of amorphous phase and metastable phase in the MM-doped magnets are also responsible for the deterioration of the magnetic properties. Overall, the performance of the ribbon is excellent when the content of the $\mathrm{MM}$ is $20 \mathrm{wt} . \%$ with $B_{\mathrm{r}}=7.38$ $\mathrm{kGs}, H_{\mathrm{cj}}=13.66 \mathrm{kOe},(B H)_{\max }=11.81$ MGOe. This conclusion provides a reference for reducing the cost of preparation of permanent magnets and the achievement comprehensive utilization of the resources.

The magnetization reversal process of the magnet is

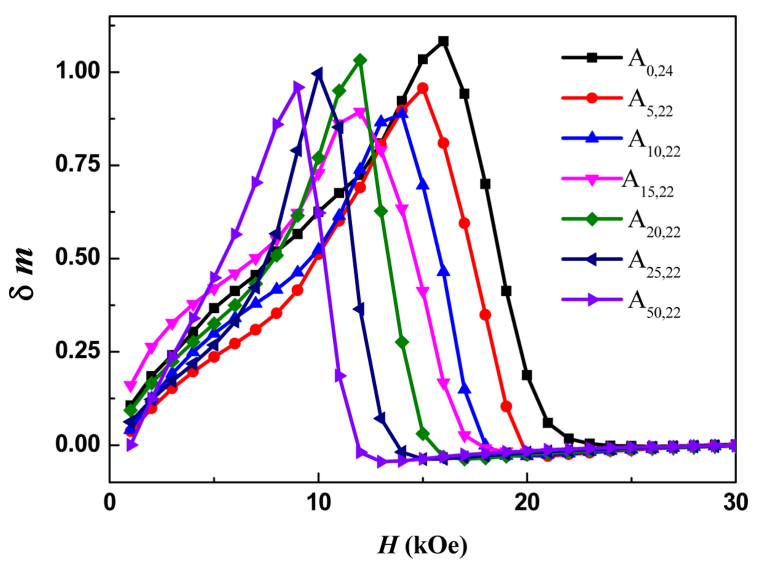

Fig. 6. (Color online) The Henkel plots of $\left(\operatorname{Pr}_{7.34} \mathrm{Nd}_{21.86}\right)_{1-\mathrm{x}^{-}}$ $\mathrm{MM}_{\mathrm{x}} \mathrm{Fe}_{68.7} \mathrm{Al}_{0.1} \mathrm{Cu}_{0.12} \mathrm{Co}_{0.88} \mathrm{~B}$ ribbons with the optimum magnetic properties at room temperature. strongly dependent on the intergranular exchange coupling. For isotropic magnet quenching, the remanence ratio $M_{\mathrm{r}} / M_{\mathrm{s}}>0.5\left(M_{\mathrm{s}}\right.$ is the magnetization at the field of 30 $\mathrm{kOe}$ ) indicates the existence of exchange coupling between the grains. Henkel plots ( $\delta m$ vs. $H$ ) may be used to examine the exchange coupling. The expression of $\delta m$ is defined as $\delta m=\left[2 M_{\mathrm{r}}(H)+M_{\mathrm{d}}(H)\right] / M_{\mathrm{r}}-1$ according to Ref. [5], where $M_{\mathrm{r}}(H)$ is the initial remanent magnetization obtained by applying a field of $H$, and $M_{\mathrm{d}}(H)$ is the remanent magnetization obtained by applying a reversal field of $H$. The competition between exchange coupling interaction and dipolar interaction can be indicated by the values of $\delta m$. The $\delta m$ curve with a positive peak reveals the existence of strong intergranular exchange coupling in isotropic samples, and the $\delta m$ curve with a negative peak implies that magnetostatic interaction is dominant.

The Henkel plots of $\left(\mathrm{Pr}_{7.34} \mathrm{Nd}_{21.86}\right)_{1-\mathrm{x}} \mathrm{MM}_{\mathrm{x}} \mathrm{Fe}_{68.7} \mathrm{Al}_{0.1^{-}}$ $\mathrm{Cu}_{0.12} \mathrm{Co}_{0.88} \mathrm{~B}$ with the optimum magnet properties at room temperature are shown in Fig. 6. Each plot shows a strong positive peak at a field close to the coercivity and subsequent a weak negative peak, indicating that the strong intergranular exchange coupling takes place in our samples. That is in agreement with the TEM results. The peak values of the Henkel plots decrease with the addition of MM content, while the peaks reduce obviously for $A_{5,22}, A_{10,22}, A_{15,22}$ and slightly for $A_{20,22}, A_{25,22}, A_{50,22}$. For the samples containing $M M$, the $A_{20,22}$ exhibits the highest peak value of $\delta m$. It means that strong intergranular exchange coupling exists in $\mathrm{A}_{20,22}$. The exchange coupling effect is not only dependent on the composition of the main phase in the magnet, but also affected by the intergrain phase. The decrease of $\delta m$ peak probably results from the changes of the main phase and homogeneity breaking of grain boundary in ribbons. Adding a small amount of MM, a part of Ce elements substitute PrNd in the main phase, and the rest exists in the grain boundary phase. This causes the change of the main phase and the non-uniform of the grain boundary phase, which leads to the rapid decrease of the peak value. The intergrain phases improve when MM content is over 15 wt.\% because La element is more likely to exist in the grain boundary [20]. Hence, a thin layer of rare-earth-phase may form between the main phase grains and the grain boundary becomes smooth, hence the maximum value of $\delta m$ increases due to the improvement of the grain boundary [18].

\section{Conclusions}

In summary, we have studied the magnetic properties of $\left(\operatorname{Pr}_{7.34} \mathrm{Nd}_{21.86}\right)_{1-\mathrm{x}} \mathrm{MM}_{\mathrm{x}} \mathrm{Fe}_{68.7} \mathrm{Al}_{0.1} \mathrm{Cu}_{0.12} \mathrm{Co}_{0.88} \mathrm{~B}$ ribbons pre- 
pared with different wheel velocities. It was found that the optimized wheel speed of the ribbons contained MM was about $22 \mathrm{~m} / \mathrm{s}$. With the increase of the amount of $\mathrm{MM}$, the coercivity, maximum energy product and remanence decreased. The intergranular exchange coupling was influenced by the addition of MM. The magnet with 15 wt.\% of MM exhibited the weakest coupling interaction. The intergranular exchange coupling was improved when the MM content is higher than $15 \mathrm{wt} . \%$. The present study could be helpful for preparing new permanent magnets with MM resource.

\section{Acknowledgements}

This paper was supported by the National of China (Nos. 11564030 and 51571126), the Research Program of Science and Technology at Universities of Inner Mongolia Autonomous Region (No. NJZZ14159), Innovative Research Team (No. 3400102), Provincial Major Science and Technology Innovation Project of Inner Mongolia (No. 2009J1006), Baotou Key Project of Rare Earth (No. 2012R1006), Science and Technology Innovation Project of University (No. 2014QDL003), Inner Mongolia Natural Science Foundation (No. 2013Ms0111).

\section{References}

[1] M. Sagawa, S. Fujimura, N. Togawa, H. Yamamoto, and Y. Matsuura, J. Appl. Phys. 55, 2083 (1984).

[2] J. J. Croat, J. F. Herbst, R. W. Lee, and F. E. Pinkerton, J. Appl. Phys. 55, 2078 (1984).

[3] K. M. Kim, H. W. Kwon, J. G. Lee, and J. H. Yu, J. Magn. 20, 21 (2015).

[4] S. Sugimoto, N. Koike, D. Book, T. Kagotani, M. Okada, K. Inomata, and M. Homma, J. Alloys Compd. 330, 892 (2012).
[5] Z. B. Li, B. G. Shen, M. Zhang, F. X. Hu, and J. R. Sun, J. Alloys Compd. 628, 325 (2015).

[6] A. Alam, M. Khan, R. W. McCallum, and D. D. Johnson, Appl. Phys. Lett. 102, 042402 (2013).

[7] X. F. Zhang, J. T. Lan, Z. B. Li, Y. L. Liu, L. L. Zhang, Y. F. Li, and Q. Zhao, Chin. Phys. B 25, 057502 (2016).

[8] M. Hussain, J. Liu, L. Z. Zhao, X. C. Zhong, G. Q. Zhang, and Z. W. Liu, J. Magn. Magn. Mater. 399, 26 (2016).

[9] J. Y. Jin, Y. J. Zhang, T. Y. Ma, and M. Yan, IEEE Trans. Magn. 18, 9464 (2015).

[10] M. Hussain, L. Z. Zhao, C. Zhang, D. L. Jiao, X. C. Zhong, and Z. W. Liu, Physica B 483, 69 (2016).

[11] J. Y. Jin, Y. J. Zhang, G. H. Bai, Z. Y. Qian, C. Wu, T. Y. Ma, B. G. Shen, and M. Yan, Scientific Reports 6, 30194 (2016).

[12] Q. A. La, C. H. Groot, F. R. Boer, and K. H. J. Buschow, J. Alloys Compd. 256, 82 (1997).

[13] A. K. Pathak, M. Khan, K. A. Gschneidner Jr., R. W. McCallum, L. Zhou, K. W. Sun, K. W. Dennis, C. Zhou, F. E. Pinkerton, M. J. Kramer, and V. K. Pecharsky, J. Adv. Mater. 27, 2663 (2015).

[14] M. G. Zhu, W. Li, J. D. Wang, L. Y. Zheng, Y. F. Li, K. Zhang, H. B. Feng, and T. Liu, IEEE Trans. Magn. 50, 1000104 (2014).

[15] E. Niu, Z. A. Chen, G. A. Chen, Y. G. Zhao, J. Zhang, X. L. Rao, B. P. Hu, and Z. X. Wang, J. Appl. Phys. 115, 113912 (2014).

[16] Z. B. Li, M. Zhang, B. G. Shen, F. X. Hu, and J. R. Sun, Mater. Lett. 172, 102 (2016).

[17] X. C. Wang, M. G. Zhu, W. Li, L. Y. Zheng, Z. H. Gou, X. Du, and A. Du, Physica B. 476, 150 (2015).

[18] M. Zhang, Z. B. Li, B. G. Shen, F. X. Hu, and J. R. Sun, J. Alloys Compd. 651, 144 (2015).

[19] Y. X. Qiang, Y. Ming, and L.W. Qiang, J. Rare Earths 34, 614 (2016).

[20] X. B. Liu, Z. Altounian, M. D. Huang, Q. M. Zhang, and J. P. Liu, J. Alloys Compd. 549, 366 (2013). 